Check for updates

Cite this: RSC Adv., 2017, 7, 32344

Received 21st March 2017

Accepted 16th June 2017

DOI: $10.1039 / c 7 r a 03310 a$

rsc.li/rsc-advances

\section{Renewable sources from plants as the starting material for designing new terpene chiral ionic liquids used for the chromatographic separation of acidic enantiomers $\dagger$}

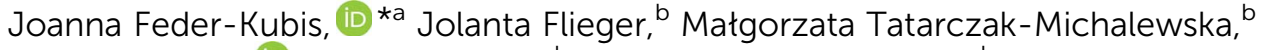
Anita Ptazińska, (D) ${ }^{c}$ Anna Madejska ${ }^{b}$ and Marta Swatko-Ossor ${ }^{d}$

Synthesis of cheap and natural resources is an important topic in green chemistry. For that reason, new chiral ionic liquids (CILs) containing a bicyclic terpene moiety were designed and prepared from renewable plant resources. The synthesis route was comprehensively described, especially a specific type of Menschutkin reaction, which gives high energy efficiency during the process. The physicochemical characteristics of the obtained chiral salts, including the spectral properties, melting point, crystal shape, specific rotation and solubility in various solvents were examined. The study presents the effect of new chiral ionic liquids as mobile phase additives on the chiral recognition of acidic enantiomers on a teicoplanin-based chiral stationary phase (CSP). Based on the van't Hoff relationships, the thermodynamic functions were determined. The plots revealed that the chiral recognition was enthalpy driven. The chiral salts obtained exhibited a synergistic effect with the teicoplanin-based stationary phase in the chromatographic system, enhancing the resolution of acidic enantiomers. Structural task-specific properties of the new terpene-based chiral ionic liquids were confirmed by molecular modeling and docking simulations.
\end{abstract}

\section{Introduction}

Ionic liquids (ILs) are defined as salts with melting points below $100{ }^{\circ} \mathrm{C}$ and have attracted researchers' attention in various fields of the chemical industry for the last few decades. They have partially replaced the organic solvents and are growing in popularity due to their ecological nature and the possibility of designing them with specific properties. They have also brought many benefits to analytical chemistry. Concerning applications in separation techniques, ILs have been used for either modification of stationary phases in gas-liquid chromatography (GLC) $)^{1,2}$ and capillary electrophoresis ${ }^{3}$ or as mobile phase additives in liquid chromatography ${ }^{4-7}$ and electrophoresis as background electrolyte modifiers. ${ }^{8,9}$ ILs are used as solvents in different extraction techniques. Whereas water-insoluble ILs are useful in liquid-liquid microextractions $s^{\mathbf{1 0 , 1 1}}$ and as

${ }^{a}$ Faculty of Chemistry, Wrocław University of Science and Technology, 50-370 Wrocław, Poland. E-mail: joanna.feder-kubis@pwr.edu.pl

${ }^{b}$ Department of Analytical Chemistry, Medical University of Lublin, 20-093 Lublin, Poland

${ }^{c}$ Department of Biopharmacy, Medical University of Lublin, 093 Lublin, Poland ${ }^{d}$ Department of Biochemistry and Biotechnology, Medical University of Lublin, 20-093 Lublin, Poland

$\dagger$ Electronic supplementary information (ESI) available. See DOI: 10.1039/c7ra03310a modifiers of adsorbents for solid phase extraction (SPE), ${ }^{\mathbf{1 2}}$ water-soluble ILs can be used as extracting solvents, thus creating aqueous biphasic systems (ABS). ${ }^{13-15}$ The overviews of the various applications of ILs in separation techniques are described extensively in review articles. ${ }^{16-18}$

One of the most interesting developments of ILs appears to be searching for new task-specific ILs by expanding their particular properties. For instance there exists a possibility of creating chiral ionic liquids (CILs) by introducing chiral centers either in the cations or anions. The application of chiral ILs for separation of enantiomers has been described previously mainly in electrophoretic techniques. ${ }^{19-23}$ It should be emphasized, however, that the much better results of enantiomers' resolution could be achieved using a few chiral selectors simultaneously, making use of the synergistic effects of such combined systems. For that purpose a few ILs or system containing chiral ILs and $\beta$-cyclodextrins or antibiotics (vancomycin) have been applied to improve enantiorecognition. ${ }^{22,24,25}$

Only a few papers have described the potential of CILs as chiral selectors in liquid chromatography. ${ }^{26-31}$ In the study by Yuan et al. ${ }^{26}$ the $(R)-N, N, N$-trimethyl-2-aminobutanol bis(trifluoromethylsulfonyl)imide ionic liquid was applied in high performance liquid chromatography (HPLC), as a chiral mobile phase modifier using C18 column. Zhou et al. ${ }^{31}$ for the first time, applied an IL-based chiral selector as a stationary phase. 
For that purpose, new ILs functionalized $\beta$-CDs were bonded to silica gel. Recently, the research on the immobilized chiral ionic liquids on a HPLC column has been described by Qian et al. ${ }^{32}$ In this work, tropine-type CILs with a proline anion were immobilized on silica gel. The chiral ionic liquid-modified silica gel saturated by $\mathrm{Cu}$ (II) was used in the resolution of racemic amino acids.

Currently particular efforts are made to design a 'fully green' ionic liquid. For this reason recently, the issues of biodegradability and toxicity of ILs have recently become of primary interest. ${ }^{33,34}$ The synthesis of ionic liquids using renewable compounds as the starting materials, e.g. terpenes, ${ }^{35}$ sugar, ${ }^{36}$ amino alcohols, ${ }^{37}$ hydroxy acids,${ }^{38}$ or amino acids ${ }^{39}$ seems to be extremely desirable.

Here we report the synthesis, characterization and application of chiral ionic liquids containing a bicyclic monoterpene moiety. As starting materials, renewable sources from plants were selected: $(1 S)$-endo-(-)-borneol and $(1 R)$-endo-(+)-fenchol. CILs with bicyclic terpene moieties were used as chiral selectors for the first time. The described synergistic system basing on a glycopeptide stationary phase with CILs as mobile phase additives has never been reported before in LC. The specific cooperative effect was used for the enantiomeric resolution of acids. The effect of different parameters on resolution was explored in detail, along with the associated thermodynamics. Moreover, in this work the molecular mechanism of stereoselective binding of enantiomers to a teicoplanin structure in the presence of CILs is discussed for the first time.

\section{Experimental}

\section{Materials and techniques}

The materials used were sourced as follows: imidazole ( $\geq 99 \%)$, 1-methylimidazole (99\%), (1S)-endo-(-)-borneol (97\%), (1R)endo-(+)-fenchol (96\%), paraformaldehyde (powder, 95\%), sodium (cubes, contains mineral oil, 99.9\% trace metals basis), 1-bromopentane (98\%), hydrochloric acid (35-38\%), sulfuric acid $(\geq 96 \%)$ were purchased from Sigma-Aldrich. Racemic standards of mandelic acid, phenyllactic acid, 4-hydroxy-3methoxymandelic acid (vanilmandelic) acid were also obtained from Sigma Aldrich (St. Louis, MO, USA). HPLC grade methanol $(\mathrm{MeOH})$ was purchased from Merck (Darmstadt, Germany). HPLC water was obtained from Barnstead deionising system (Dubuque, IA, USA). All mobile phases were filtered with Nylon 66 membrane filters $(0.45 \mu \mathrm{m})$ by Whatman (Maidstone, England) by the use of a filtration apparatus. Stock solutions of individual racemic acids at $1.0 \mathrm{mg} \mathrm{L}^{-1}$ were prepared in methanol and stored in glass vials in refrigerator.

For NMR analysis, deuterated chloroform $\left(\mathrm{CDCl}_{3}\right)$ purchased from Merck was used. All the solvents were dried before use. All reagents were dried and purified before use by the usual procedures; reactions were performed under anhydrous conditions.

Melting points were determined by using an electrothermal digital-melting-point apparatus model JA 9100 (temperature resolution $\pm 0.1{ }^{\circ} \mathrm{C}$; accuracy $\pm 1 \%$; choice of ramp rate of $1.0{ }^{\circ} \mathrm{C}$ $\min ^{-1}$ ). The type and the shape of the crystals were analysed via an optical microscope AxioImager M1m (Zeiss) in reflection mode. Specific rotations at $578 \mathrm{~nm}$ were measured using an Optical Activity Ltd. Model AA-5 automatic polarimeter (resolution $\pm 0.01^{\circ}$, reproducibility $\pm 0.01^{\circ}$, accuracy $\pm 0.01^{\circ}$, temperature probe measurement accuracy $\pm 0.1{ }^{\circ} \mathrm{C}$, the equipment provide four results for each measurement). The structure and purity of all of the synthesized salts were confirmed by spectral analysis. Elemental analyses were carried out for all of the synthesized substances using VARIO EL-III. The ${ }^{1} \mathrm{H}$ NMR and ${ }^{13} \mathrm{C}$ NMR spectra were recorded on a Bruker DRX instrument with tetramethylsilane as standard (at 600 and $75 \mathrm{MHz}$, respectively). HRMS analyses were performed on LCT Premier XE Waters apparatus, on mode ESI+ (TOF MS ES+). Elemental analyses were carried out for all of the synthesised substances using a VARIO EL-III.

\section{General methods for synthesis}

Imidazole was freshly recrystallized from benzene (mp 90-91 $\left.{ }^{\circ} \mathrm{C}\right)$. 1-Methylimidazole was purchased, while 1-pentylimidazole was obtained following the published method. ${ }^{40}$ These 1-alkylimidazoles were purified by vacuum distillation before use in a quaternization reaction.

\section{Synthesis of the quaternary agents}

Method for the synthesis of the chloromethyl terpenyl ethers (1a and 2a). Gaseous hydrogen chloride was introduced with mechanical stirring into a mixture of proper terpene alcohol: $(1 S)$-endo-(-)-borneol $(52.455 \mathrm{~g}, 0.34 \mathrm{~mol})$ or $(1 R)$-endo-(+)-fenchol $(52.455 \mathrm{~g}, 0.34 \mathrm{~mol})$, toluene $(100 \mathrm{~mL})$ and paraformaldehyde (10.51 g, $0.35 \mathrm{~mol})$ until the solution was saturated. The reaction using (1S)-endo-(-)-borneol took approximately five hours, whereas the process using $(1 R)$-endo$(+)$-fenchol as a substrate was faster and was carried out for roughly three hours. Each process was conducted under isothermal conditions at $10{ }^{\circ} \mathrm{C}$. Water was removed and then the reaction mixture was dried over sodium sulphate. Subsequently, the hydrogen chloride absorbed in the reaction product was stripped off with dry nitrogen and finally the solvent was evaporated under reduced pressure. Through these means, two chloromethyl terpenyl ethers were obtained. The crude (1S)-endo-(-)-bornyl chloromethyl ether (1a) was performed in the form of yellow liquid, whereas the reaction of producing chloromethyl (1R)-endo-(+)-fenchyl ether (2a) gave a tea-coloured liquid.

The amount of each of chloromethyl terpenyl ethers in the final product was determined by the alkalimetric method (alkalimetric titration of the $\mathrm{HCl}$ obtained as a result of ether hydrolysis), according to the procedure described earlier by our group for chloromethyl $(1 R, 2 S, 5 R)-(-)$-menthyl ether, ${ }^{\mathbf{4 1}}$ as follows: $1 \mathrm{~g}$ crude product (ether) was added to $10 \mathrm{~mL}$ acetone at $-20{ }^{\circ} \mathrm{C}$. The possible free $\mathrm{HCl}$ absorbed in the sample was quickly neutralized with $0.02 \mathrm{M} \mathrm{KOH}$ in $\mathrm{MeOH}$. Hot water (5 $\mathrm{mL}$ ) was then added. $\mathrm{HCl}$ as a product of hydrolysis of ether was neutralized with $0.2 \mathrm{M} \mathrm{KOH}$ in $\mathrm{MeOH}$. The crude product contained $95.0 \%$ and $97.0 \%$ of chloromethyl (1S)-endo(-)-bornyl ether (1a) and chloromethyl (1R)-endo-(+)-fenchyl (2a) 
respectively. The chloromethyl terpenyl ethers obtained were purified by vacuum distillation to give clear liquids and the process was repeated each time before used them as quaternary agents in the Menschutkin reaction.

(1S)-endo-(-)-Bornyl chloromethyl ether (1a). Vacuum distillation conditions: bp $85-86{ }^{\circ} \mathrm{C}$ at $1 \mathrm{mmHg}$ (yield: $93.5 \%$, $0.318 \mathrm{~mol}, 64.467 \mathrm{~g})$. Elemental analysis calc. (\%) for $\mathrm{C}_{11} \mathrm{H}_{19} \mathrm{ClO}$ (202.75): C 65.16, H 9.46, found: C 65.22, H 9.53.

Chloromethyl (1R)-endo-(+)-fenchyl ether (2a). Vacuum distillation conditions: bp $76-77{ }^{\circ} \mathrm{C}$ at $1 \mathrm{mmHg}$ (yield: $96.5 \%$, $0.328 \mathrm{~mol}, 66.535 \mathrm{~g})$. Elemental analysis calc. (\%) for $\mathrm{C}_{11} \mathrm{H}_{19} \mathrm{ClO}$ (202.75): C 65.16, H 9.46, found: C 65.14, H 9.56.

\section{Synthesis of the chiral ionic liquids - Menschutkin quaternization}

Method for the synthesis of the 3-alkyl-1terpenoxymethylimidazolium chlorides (1b, 1c, 2b, and 2c). The quaternary imidazolium salts containing natural bicyclic terpene moiety were performed under anhydrous conditions. Chloromethyl (1S)-endo-(-)-bornyl ether 1a $(6.285 \mathrm{~g}, 0.031 \mathrm{~mol})$ or chloromethyl (1R)-endo-(+)-fenchyl ether 2a (6.285 g, 0.031 $\mathrm{mol}$ ), distilled just before the reaction, was added dropwise into a three-necked, round-bottomed flask equipped with a mechanical stirrer, reflux condenser, and thermometer which contained a vigorously stirred mixture of $30 \mathrm{~mL}$ dry hexane and freshly distilled 1-alkylimidazole $(0.03 \mathrm{~mol})$. The reaction mixture was stirred at room temperature for two hours. The progress of each reaction was monitored by ascending thin layer chromatography (TLC) on silica gel G (Merck 1.05570.0001), and visualized by UV light. The white precipitate produced was removed by filtration and then washed with dry hexane $(3 \times 30$ $\mathrm{mL})$. The volatile materials were removed under reduced pressure $(0.3 \mathrm{mmHg})$ at $40{ }^{\circ} \mathrm{C}$ overnight. The obtained white solids were crystallized, and further dried in vacuum $(0.3 \mathrm{mmHg})$ to get analytically pure salts in yields of 97.6.5-99.6\%. Prior to any measurements, the 3-alkyl-1-terpenoxymethylimidazolium chlorides samples were dried for 48 hours under vacuum.

1-[(1S)-endo-(-)-Borneoxymethyl]-3-methylimidazolium chloride $\left[\mathrm{C}_{1}-\mathrm{Im}-\mathrm{CH}_{2} \mathrm{O}-\mathrm{Bor}\right][\mathrm{Cl}](\mathbf{1 b})$. Yield: $99.4 \%, 0.0298 \mathrm{~mol}, 8.495 \mathrm{~g}$. ${ }^{1} \mathrm{H}$ NMR: $\left(600 \mathrm{MHz}, \mathrm{CDCl}_{3}\right): \delta=0.76(\mathrm{~s}, 3 \mathrm{H}$, bor. $), 0.79-0.84(\mathrm{~m}$, 6H, bor.), 0.86-0.92 (m, 1H, bor.), 1.15-1.24 (m, 2H, bor.), 1.6351.65 (m, 1H, bor.), 1.67-1.72 (m, 1H, bor.), 1.86-1.90 (m, 1H, bor.), 2.21-2.25 (m, 1H, bor.), 3.83 (d, J=9.0 Hz, 1H, bor. $C H-O)$, $4.14\left(\mathrm{~s}, 3 \mathrm{H}, \mathrm{N}-\mathrm{CH}_{3}\right), 5.69$ and $5.79(\mathrm{~d}, \mathrm{~J}=10.2 \mathrm{~Hz}, 2 \mathrm{H}, \mathrm{AB}$ system, $\mathrm{O}-\mathrm{CH}_{2}-\mathrm{N}$ ), 7.46 (s, 1H, imi.), 7.64 (s, 1H, imi.), 10.81 (s, 1H, imi.). ${ }^{13} \mathrm{C}$ NMR (151 MHz, $\mathrm{CDCl}_{3}$ ): $\delta=13.55$ (bor.), 18.95 (bor.), 19.6 (bor.), 26.4 (bor.), 28.0 (bor.), 35.9 (bor.), $36.8\left(\mathrm{~N}-\mathrm{CH}_{3}\right), 44.9$ (bor.), 47.7 (bor.), 49.3 (bor.), 78.7 (bor. $\mathrm{CH}-\mathrm{O}), 86.0\left(\mathrm{O}-\mathrm{CH}_{2}-\mathrm{N}\right), 120.7$ (imi.), 123.9 (imi.), 138.2 (imi.). HRMS (ESI+): $\mathrm{m} / \mathrm{z}$ (\%) calcd for $\mathrm{C}_{15} \mathrm{H}_{25} \mathrm{~N}_{2} \mathrm{O}: 249.1967$, found: 249.1960 . Elemental analysis calc. (\%) for $\mathrm{C}_{15} \mathrm{H}_{25} \mathrm{ClN}_{2} \mathrm{O}$ (284.87): C 63.24, $\mathrm{H}$ 8.86, N 9.84, found: $\mathrm{C}$ 63.35, H 8.99, N 9.70.

1-[(1S)-endo-(-)-Borneoxymethyl]-3-pentylimidazolium chloride [C $\left.\mathrm{C}_{5} \mathrm{Im}-\mathrm{CH}_{2} \mathrm{O}-\mathrm{Bor}\right][\mathrm{Cl}](\mathbf{1 c})$. Yield: $97.6 \%, 0.0293 \mathrm{~mol}, 9.984 \mathrm{~g} .{ }^{1} \mathrm{H}$ NMR: (600 MHz, $\left.\mathrm{CDCl}_{3}\right): \delta=0.755$ (s, 3H, bor.), 0.82-0.90 (m, 10H, 7H: bor., 3H: $\left.\mathrm{N}-\mathrm{CH}_{2} \mathrm{CH}_{2} \mathrm{CH}_{2} \mathrm{CH}_{2} \mathrm{CH}_{3}\right)$, 1.15-1.25 (m, $2 \mathrm{H}$, bor.), $1.305-1.39\left(\mathrm{~m}, 4 \mathrm{H}, \mathrm{N}-\mathrm{CH}_{2} \mathrm{CH}_{2} \mathrm{CH}_{2} \mathrm{CH}_{2} \mathrm{CH}_{3}\right.$ ), 1.64-1.65 (m, 1H, bor.), 1.69-1.71 (m, 1H, bor.), 1.865-1.965 (m, 3H, 1H: bor., $2 \mathrm{H}$ : $\mathrm{N}-\mathrm{CH}_{2} \mathrm{CH}_{2} \mathrm{CH}_{2} \mathrm{CH}_{2} \mathrm{CH}_{3}$ ), 2.21-2.23 (m, 1H, bor.), 3.863.88 (m, 1H, bor. $\mathrm{CH}-\mathrm{O})$, 4.36-4.38 (m, 2H, $\mathrm{N}-\mathrm{CH}_{2} \mathrm{CH}_{2} \mathrm{CH}_{2}$ $\mathrm{CH}_{2} \mathrm{CH}_{3}$ ), 5.74 and 5.85 (d, $\mathrm{J}=10.2 \mathrm{~Hz}, 2 \mathrm{H}, \mathrm{AB}$ system, $\mathrm{O}_{-} \mathrm{CH}_{2}-$ N), 7.47 (s, 1H, imi.), 7.475 (s, 1H, imi.), 11.01 (s, 1H, imi.). ${ }^{13} \mathrm{C}$

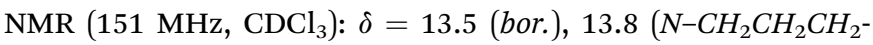
$\mathrm{CH}_{2} \mathrm{CH}_{3}$ ), 18.95 (bor.), 19.6 (bor.), $22.0\left(\mathrm{~N}-\mathrm{CH}_{2} \mathrm{CH}_{2} \mathrm{CH}_{2} \mathrm{CH}_{2} \mathrm{CH}_{3}\right.$ ), 26.4 (bor.), 28.0 (bor.), $28.2\left(\mathrm{~N}_{-} \mathrm{CH}_{2} \mathrm{CH}_{2} \mathrm{CH}_{2} \mathrm{CH}_{2} \mathrm{CH}_{3}\right.$ ), 29.9 ( $\mathrm{N}-$ $\mathrm{CH}_{2} \mathrm{CH}_{2} \mathrm{CH}_{2} \mathrm{CH}_{2} \mathrm{CH}_{3}$ ), 35.9 (bor.), 44.9 (bor.), 47.7 (bor.), 49.3 (bor.), $50.15\left(\mathrm{~N}-\mathrm{CH}_{2} \mathrm{CH}_{2} \mathrm{CH}_{2} \mathrm{CH}_{2} \mathrm{CH}_{3}\right.$ ), 78.7 (bor. $\left.\mathrm{CH}-\mathrm{O}\right), 86.0(\mathrm{O}-$ $\mathrm{CH}_{2}-\mathrm{N}$ ), 121.0 (imi.), 122.6 (imi.), 138.5 (imi.). HRMS (ESI+): $\mathrm{m} / \mathrm{z}$ (\%) calcd for $\mathrm{C}_{19} \mathrm{H}_{33} \mathrm{~N}_{2} \mathrm{O}$ : 305.2593, found: 305.2605. Elemental analysis calc. (\%) for $\mathrm{C}_{19} \mathrm{H}_{33} \mathrm{ClN}_{2} \mathrm{O}$ (340.99): $\mathrm{C} 66.92, \mathrm{H} 9.77, \mathrm{~N}$ 8.22, found: C 66.83, H 9.91, N 8.30.

1-[(1R)-endo-(+)-Fenchoxymethyl]-3-methylimidazolium chloride $\left[\mathrm{C}_{1}-\mathrm{Im}-\mathrm{CH}_{2} \mathrm{O}-\mathrm{Fen}\right][\mathrm{Cl}](2 \boldsymbol{b})$. Yield: $99.6 \%, 0.0299 \mathrm{~mol}, 8.512 \mathrm{g.}{ }^{1} \mathrm{H}$ NMR: (600 MHz, $\left.\mathrm{CDCl}_{3}\right): \delta=0.83(\mathrm{~s}, 3 \mathrm{H}$, fen. $), 0.92-1.01(\mathrm{~m}, 7 \mathrm{H}$, fen.), 1.06-1.08 (m, 1H, fen.), 1.34-1.40 (m, 1H, fen.), 1.44-1.46 (m, 1H, fen.), 1.61-1.64 (m, 3H, fen.), 3.19 (s, 1H, fen. CH-O), $4.14\left(\mathrm{~s}, 3 \mathrm{H}, \mathrm{N}-\mathrm{CH}_{3}\right), 5.68$ and $5.72(\mathrm{~d}, J=10.8 \mathrm{~Hz}, J=10.3 \mathrm{~Hz}$, 2H, AB system, $\mathrm{O}-\mathrm{CH}_{2}-\mathrm{N}$ ), 7.455 (s, 1H, imi.), 7.72 (s, 1H, imi.), 10.82 (s, 1H, imi.). ${ }^{13} \mathrm{C}$ NMR (151 MHz, $\mathrm{CDCl}_{3}$ ): $\delta=19.4$ (fen.), 21.0 (fen.), 25.75 (fen.), 25.8 (fen.), 31.3 (fen.), $36.7\left(\mathrm{~N}-\mathrm{CH}_{3}\right), 39.4$ (fen.), 41.0 (fen.), 48.4 (fen.), 48.9 (fen.), 79.3 (fen. $\mathrm{CH}-\mathrm{O}), 93.7$ (O$\mathrm{CH}_{2}-\mathrm{N}$ ), 120.9 (imi.), 124.05 (imi.), 138.2 (imi.). HRMS (ESI+): $\mathrm{m} / \mathrm{z}$ (\%) calcd for $\mathrm{C}_{15} \mathrm{H}_{25} \mathrm{~N}_{2} \mathrm{O}$ : 249.1967 , found: 249 , 1972. Elemental analysis calc. (\%) for $\mathrm{C}_{15} \mathrm{H}_{25} \mathrm{ClN}_{2} \mathrm{O}$ (284.87): $\mathrm{C} 63.24, \mathrm{H} \mathrm{8.86,} \mathrm{N}$ 9.84, found: C 63.17, H 8.94, N 9.90.

1-[(1R)-endo-(+)-Fenchoxymethyl]-3-pentylimidazolium chloride [C ${ }_{5}$-Im- $\left.\mathrm{CH}_{2} \mathrm{O}-\mathrm{Fen}\right][\mathrm{Cl}](2 \mathrm{c})$. Yield: $98.8 \%, 0.0296 \mathrm{~mol}, 10.107 \mathrm{~g} .{ }^{1} \mathrm{H}$ NMR: (600 MHz, $\left.\mathrm{CDCl}_{3}\right): \delta=0.84$ (s, 3H, fen.), 0.88-0.90 (m, 3H, $\mathrm{N}-\mathrm{CH}_{2} \mathrm{CH}_{2} \mathrm{CH}_{2} \mathrm{CH}_{2} \underline{\mathrm{CH}}_{3}$ ), 0.935-1.02 (m, 7H, fen.), 1.02-1.09 (m, 1H, fen. $), 1.31-1.42\left(\mathrm{~m}, 5 \mathrm{H}, 1 \mathrm{H}:\right.$ fen., $4 \mathrm{H}: \mathrm{N}_{-} \mathrm{CH}_{2} \mathrm{CH}_{2}-$ $\underline{\mathrm{CH}}_{2} \underline{\mathrm{CH}}_{2} \mathrm{CH}_{3}$ ), 1.47-1.49 (m, 1H, fen.), 1.625-1.66 (m, 3H, fen.), 1.91-1.92 (m, 2H, $\left.\mathrm{N}-\mathrm{CH}_{2} \mathrm{CH}_{2} \mathrm{CH}_{2} \mathrm{CH}_{2} \mathrm{CH}_{3}\right), 3.24$ (s, $1 \mathrm{H}$, fen. $\mathrm{CH}-$ $\mathrm{O})$, 4.37-4.40 (m, 2H, $\left.\mathrm{N}-\underline{\mathrm{CH}}_{2} \mathrm{CH}_{2} \mathrm{CH}_{2} \mathrm{CH}_{2} \mathrm{CH}_{3}\right), 5.74$ and 5.79 (d, $J=10.2 \mathrm{~Hz}, 2 \mathrm{H}, \mathrm{AB}$ system, $\left.\mathrm{O}-\mathrm{CH}_{2}-\mathrm{N}\right), 7.46(\mathrm{t}, J=1.8 \mathrm{~Hz}, 1 \mathrm{H}$, imi.), 7.47 (t, $J=1.8 \mathrm{~Hz}, 1 \mathrm{H}$, imi.), 10.89 (s, $1 \mathrm{H}$, imi.). ${ }^{13} \mathrm{C} \mathrm{NMR}$ (151 MHz, $\left.\mathrm{CDCl}_{3}\right): \delta=13.8\left(\mathrm{~N}-\mathrm{CH}_{2} \mathrm{CH}_{2} \mathrm{CH}_{2} \mathrm{CH}_{2} \mathrm{CH}_{3}\right), 19.4$ (fen.), 21.0 (fen.), $22.0\left(\mathrm{~N}-\mathrm{CH}_{2} \mathrm{CH}_{2} \mathrm{CH}_{2} \mathrm{CH}_{2} \mathrm{CH}_{3}\right.$ ), 25.75 (fen.), 25.8 (fen.), $28.25\left(\mathrm{~N}-\mathrm{CH}_{2} \mathrm{CH}_{2} \mathrm{CH}_{2} \mathrm{CH}_{2} \mathrm{CH}_{3}\right), 29.9\left(\mathrm{~N}-\mathrm{CH}_{2} \mathrm{CH}_{2} \mathrm{CH}_{2} \mathrm{CH}_{2} \mathrm{CH}_{3}\right)$, 31.2 (fen.), 39.4 (fen.), 41.0 (fen.), 48.4 (fen.), 49.0 (fen.), $50.2(\mathrm{~N}-$ $\mathrm{CH}_{2} \mathrm{CH}_{2} \mathrm{CH}_{2} \mathrm{CH}_{2} \mathrm{CH}_{3}$ ), 79.5 (fen. $\left.\mathrm{CH}-\mathrm{O}\right), 93.9\left(\mathrm{O}-\mathrm{CH}_{2}-\mathrm{N}\right), 121.0$ (imi.), 122.2 (imi.), 138.5 (imi.). HRMS (ESI+): $\mathrm{m} / \mathrm{z}$ (\%) calcd for $\mathrm{C}_{19} \mathrm{H}_{33} \mathrm{~N}_{2} \mathrm{O}: 305.2593$, found: 305.2601 . Elemental analysis calc. (\%) for $\mathrm{C}_{19} \mathrm{H}_{33} \mathrm{ClN}_{2} \mathrm{O}$ (340.99): C 66.92, H 9.77, $\mathrm{N}$ 8.22, found: $\mathrm{C}$ 67.02, H 9.82, N 8.15.

\section{Solubility of chiral ionic liquids}

The solubility of obtained CILs was determined according to Vogel's Textbook of Practical Organic Chemistry. ${ }^{\mathbf{4 2}}$ The measurements were conducted for all of the synthesized chlorides at $20{ }^{\circ} \mathrm{C}$ and at $50{ }^{\circ} \mathrm{C}$ under ambient pressure for popular representative solvents. The term complete solubility refers to those salts which follow the rule: $0.1 \mathrm{~g}$ of each salts is soluble in 
$1 \mathrm{~mL}$ of solvent, while the phrase limited solubility means that $0.1 \mathrm{~g}$ of each of the investigated chlorides is dissolved in $3 \mathrm{~mL}$ of solvent. The term insoluble specifies those CILs which are not soluble ( $0.1 \mathrm{~g}$ of each) in $3 \mathrm{~mL}$ of solvent.

\section{Chromatographic instrument and conditions}

Experiments were performed using a LaChrom HPLC Merck Hitachi (E.Merck, Darmstadt, Germany) model equipped with diode array detector (DAD). The column $(150 \mathrm{~mm} \times 4.6 \mathrm{~mm}$ I.D.) was packed with $5 \mu \mathrm{m}$ Astec Chirobiotic $\mathrm{T}$ (Sigma-Aldrich, St. Louis, MO, USA). The void volume was $1.2 \mathrm{~mL}$ established by injection of blank mobile phase. Retention data were recorded

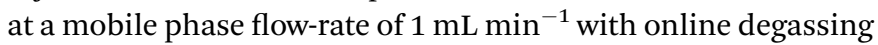
using L-7612 solvent degasser. The column temperature was controlled by a JetStream II Plus thermostat. In all experiments, the column temperature was kept at $20{ }^{\circ} \mathrm{C}$, except when the effect of temperature was evaluated. In the latter case, the temperature varied from 5 to $35^{\circ} \mathrm{C}$. The signals on HPLC system with a multiple wavelength UV detector were recorded at $220 \mathrm{~nm}$. Typical injection volumes were $5 \mu \mathrm{L}$. The elution was carried out in the isocratic mode by mobile phase consisted of $10 \%$ methanol in water and appropriate concentration of additives ranging from 5 to $20 \mathrm{mM}$.

\section{Thermodynamics}

The thermodynamics was evaluated through the determination of chromatographic retention parameter $k$ at different column temperatures using the following equation:

$$
\ln k=-\frac{\Delta H^{0}}{R} \frac{1}{T}+\frac{\Delta S^{0}}{R}+\ln \Phi
$$

where $k$ is the retention factor of the analyte, $\Delta S^{0}$ and $\Delta H^{0}$ are standard entropy change and standard enthalpy change respectively, $R$ is the ideal gas constant, $T$ is the absolute temperature, $\Phi$ is the phase ratio. For a linear curve representing ln $k$ vs. $1 / T,-\Delta H^{0} / R$ represents the slope and $\Delta S^{0} / R+$ $\ln \Phi$ represents intercept of the above relationship. Multiplying the slope and the intercept values by $R$, standard enthalpy change and entropy variations $\left(\Delta S^{0 *}\right)$ biased by $R \ln \Phi$ could be calculated respectively. The term $\Delta S^{0 *}$ can be used to represent the entropy change directly. This bias is eliminated for $\Delta(\Delta S)$ value considering the fact that the bias is constant for the particular column.

\section{Docking methodology}

The structure of teicoplanin was modeled on the basis of the available crystal structure (PDB: 5AWV). ${ }^{43}$ The crystal structure of teicoplanin was additionally functionalized by adding the three carbohydrate moieties $\left(\mathrm{O}_{1}\right.$-linked $N$-acetyl- $\beta$-D-glucosamine, $\mathrm{O}_{1}$-linked $N$-decane- $\beta$-D-glucosamine and $\mathrm{O}_{1}$-linked $\alpha$-Dmannose), which corresponds to teicoplanin immobilized on the stationary phase [Astec Chirobiotic T column (SigmaAldrich, St. Louis, MO, USA)]. The structural model of teicoplanin was built by using Avogadro 1.1.1 (ref. 44) and optimized within the UFF force field. ${ }^{45}$ In the next step, the geometry of teicoplanin was reoptimized at the PM6 (ref. 46) level of theory using Gaussian09. ${ }^{47}$ The carboxyl and amine moieties of teicoplanin were set as charged, according to the condition under physiological $\mathrm{pH}$. The enantiomers, as well as the chiral ionic liquids, were prepared using Avogadro and optimized using the UFF force field. Docking simulations were performed in the Molegro Virtual Docker software (MVD v. 2010.4.0.0), according to the methodology described in our previous paper. ${ }^{48}$ The flexible, optimized ligands of chiral ionic liquids and two enantiomers of mandelic acid, vanilmandelic and phenyllactic acid were docked into the sphere that included all four binding cavities of teicoplanin, Fig. 3. The estimation of the ligandprotein interactions was described by the MVD implemented scoring function (MolDock Score). ${ }^{49}$ The predicted positions of the ligands docked into teicoplanin were characterized by a simultaneous lowering of the scoring function value, MolDock Score $\left[\mathrm{kJ} \mathrm{mol}^{-1}\right]$; this corresponds to the high values of the ligand binding energy. The enantiomers of mandelic acid, vanilmandelic and phenyllactic acid were docked into: (i) the teicoplanin molecule and (ii) the chiral ionic liquid-teicoplanin complex. Regarding step (ii), the chiral ionic liquid was initially docked to teicoplanin and the complexes obtained (characterized by the lowest values MolDock Score) were optimized in Avogadro (UFF force field).

\section{Results and discussion}

\section{The synthesis of the chiral ionic liquids containing the natural bicyclic terpene moiety}

Several chiral imidazolium salts with a terpene moiety and chloride anion were prepared by Menschutkin reaction (Scheme 1). As starting materials, renewable sources from plants were selected: (i) (1S)-endo-(-)-borneol (1) and (ii) (1R)-endo-(+)-fenchol (2) being bicyclic compounds.

Chloromethyl terpenyl ethers were prepared first, namely (1S)-endo-(-)-bornyl chloromethyl ether (1a) and chloromethyl $(1 R)$-endo-(+)-fenchyl ether $(\mathbf{2 a})$. These quaternary agents were obtained by chloromethylation of the appropriate terpene alcohol. Such ethers are excellent reagents for quaternization, but they readily hydrolyze to $\mathrm{HCl}, \mathrm{CH}_{2} \mathrm{O}$, and proper terpene alcohol. Therefore the process of performing chloromethyl terpenyl ethers should be conducted under strictly anhydrous conditions. The obtained ethers were purified by vacuum distillation to give final products with satisfactory yields, greater than from $93.5 \%$ in each case (Table 1).

The chiral imidazolium chlorides containing terpene moiety were prepared by the Menschutkin reaction. Quaternization was achieved using distilled 1-alkylimidazole and freshly distilled appropriate chloromethyl terpenyl ether under strictly anhydrous conditions. The reaction was carried out in anhydrous hexane at room temperature, and the product precipitated from such solution. Quaternization takes place immediately and proceeds readily at room temperature according to an $S_{N} 1$ mechanism. ${ }^{41}$ This reaction has a high product yield of 97.6 to 99.6\%. Due to the fact that used chloromethyl terpenyl ethers (1a and 2a) are very reactive and quaternization takes place immediately, particular attention should be paid to increasing 


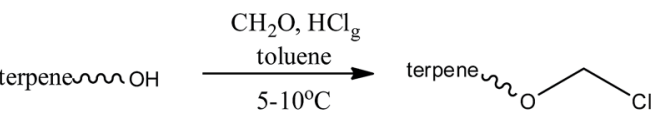

bicyclic terpene alcohols $(1 ; 2)$

\begin{tabular}{c|}
\hline natural \\
terpene alcohols \\
\hline
\end{tabular}

chloromethyl terpenyl ether

(1a; 2a) quaternary agents

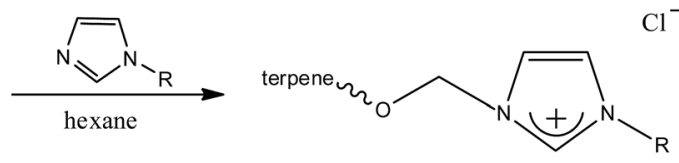

3-alkyl-1-terpenoxymethylimidazolium chlorides

(1b, 1c; 2b, 2c)

$\mathrm{Cl}^{-}$

terpene based chiral ionic liquids

$\mathrm{R}=\mathrm{CH}_{3} ; \mathrm{C}_{5} \mathrm{H}_{11}$
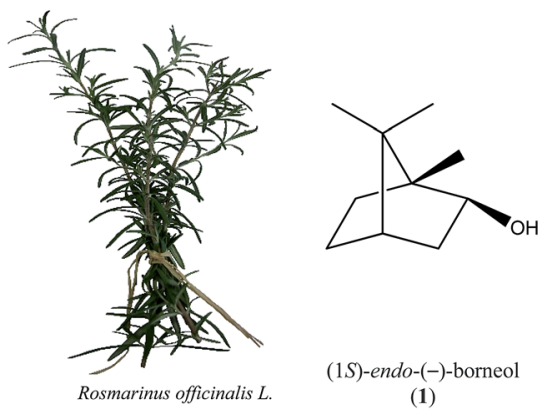

(1S)-endo-(-)-borneol

(1)

Bicyclic terpene alcohol

Scheme 1 The synthesis of the chiral ionic liquids with bicyclic monoterpene moiety.

temperature during the process. For this reason quaternization should be carried out using a reflux condenser.

Table 2 contains a list of 3-alkyl-1-[(1S)-endo-(-)-borneoxymethyl]imidazolium chlorides $\left(\left[\mathrm{C}_{1}-\mathrm{Im}_{-} \mathrm{CH}_{2} \mathrm{O}-\mathrm{Bor}\right][\mathrm{Cl}]\right.$ and $\left[\mathrm{C}_{5}-\right.$ $\left.\left.\mathrm{Im}-\mathrm{CH}_{2} \mathrm{O}-\mathrm{Bor}\right][\mathrm{Cl}]\right)$ and 3-alkyl-1-[(1R)-endo-(+)-fenchoxymethyl] imidazolium chlorides $\left(\left[\mathrm{C}_{1}\right.\right.$-Im- $\left.\mathrm{CH}_{2} \mathrm{O}-\mathrm{Fen}\right][\mathrm{Cl}]$ and $\left[\mathrm{C}_{5}\right.$ - $\mathrm{Im}-\mathrm{CH}_{2} \mathrm{O}$ $\mathrm{Fen}][\mathrm{Cl}]$ ) which have not been described in the literature before. All of the synthesized 3-alkyl-1-terpenoxymethylimidazolium chlorides are hydrophilic and are stable both in air and in aqueous solutions. The purities of the discussed crystallized

Table 1 Structure, name and yield of chiral quaternary agents (1 and 2)

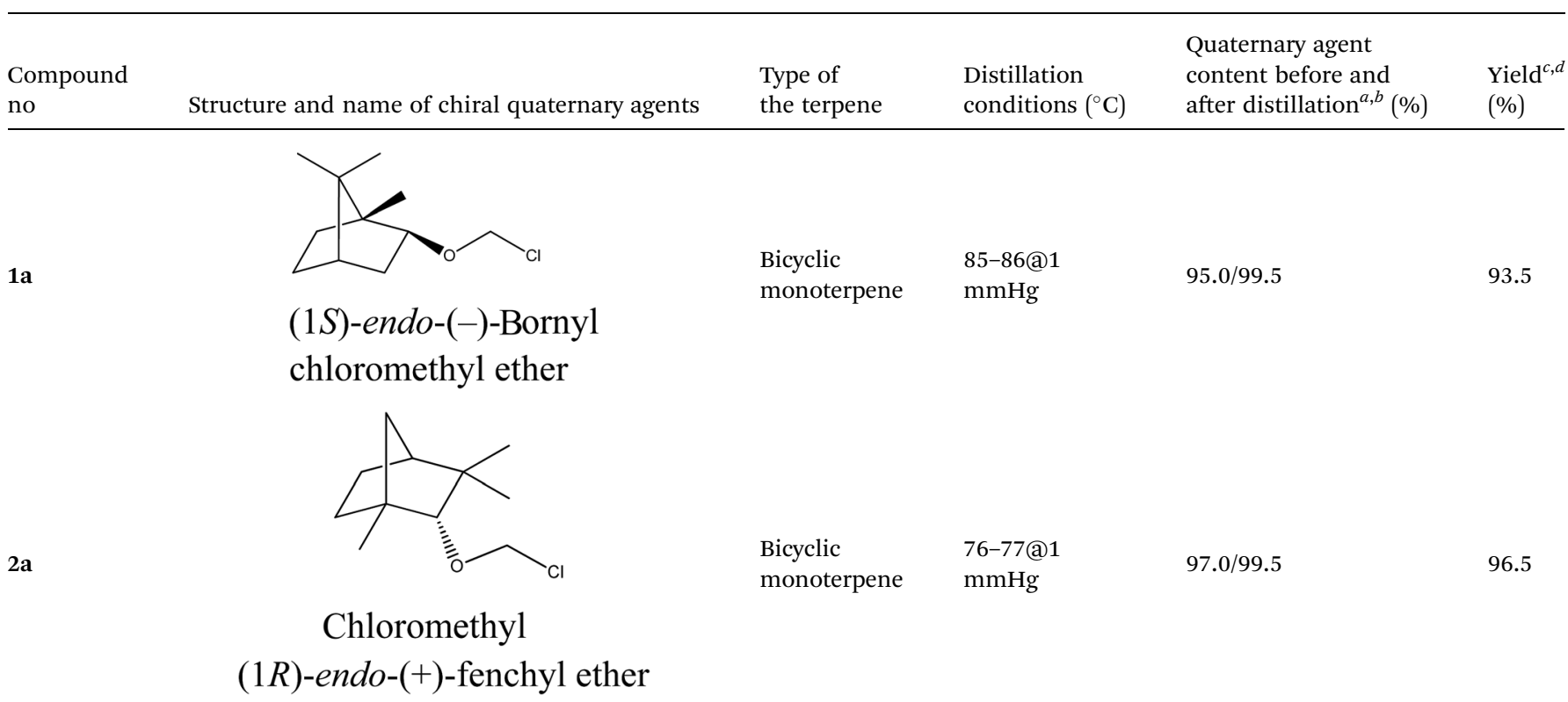

\footnotetext{
${ }^{a}$ Isolated amount of quaternary agent in the product by alkalimetric titration before and after vacuum distillation. ${ }^{b}$ Accuracy $\pm 0.5 \% .{ }^{c}$ Isolated yield after vacuum distillation. ${ }^{d}$ Accuracy $\pm 0.5 \%$.
} 
Table 2 Structure, name, abbreviation and yield of chiral ionic liquids derived from natural bicyclic terpene, 3-alkyl-1-terpenoxymethylimidazolium chlorides (1b, 1c; $2 b$, and $2 c$ )

\begin{tabular}{|c|c|c|c|c|c|}
\hline CILs & Structure & $\mathrm{R}$ & $\begin{array}{l}\text { Name of chiral ionic } \\
\text { liquids based on terpene }\end{array}$ & $\begin{array}{l}\text { Abbreviation } \\
{\left[\text { Cn-Im- } \mathrm{CH}_{2} \mathrm{O} \text {-Terpene }\right][\mathrm{Cl}]}\end{array}$ & $\begin{array}{l}\text { Yield }^{a, b} \\
(\%)\end{array}$ \\
\hline
\end{tabular}

(1S)-endo-(-)-Borneol based chiral ionic liquids

3-Alkyl-1-[(1S)-endo-(-)-borneoxymethyl]imidazolium chlorides

$1 \mathbf{b}$<smiles></smiles>

1c

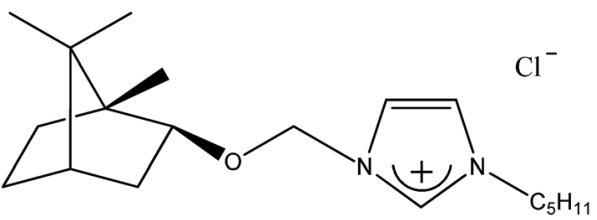

$\mathrm{CH}_{3}$ 1-[(1S)-endo-(-)-Borneoxymethyl]-3methylimidazolium chloride

$\left[\mathrm{C}_{1}-\mathrm{Im}-\mathrm{CH}_{2} \mathrm{O}-\mathrm{Bor}\right][\mathrm{Cl}]$

99.4

$\mathrm{C}_{5} \mathrm{H}_{11} \quad$ 1-[(1S)-endo-(-)-Borneoxymethyl]-3pentylimidazolium chloride
$\left[\mathrm{C}_{5}-\mathrm{Im}-\mathrm{CH}_{2} \mathrm{O}-\mathrm{Bor}\right][\mathrm{Cl}]$

97.6

(1R)-endo-(+)-Fenchol based chiral ionic liquids

3-Alkyl-1-[(1R)-endo-(+)-fenchoxymethyl]imidazolium chlorides

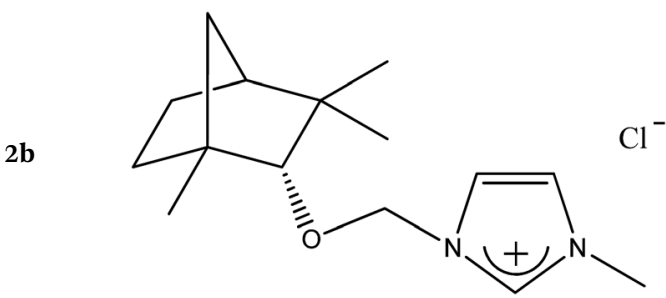

$\mathrm{CH}_{3}$

1-[(1R)-endo-(+)-Fenchoxymethyl]-3methylimidazolium chloride

$\left[\mathrm{C}_{1}\right.$-Im- $\left.-\mathrm{CH}_{2} \mathrm{O}-\mathrm{Fen}\right][\mathrm{Cl}]$

$2 c$

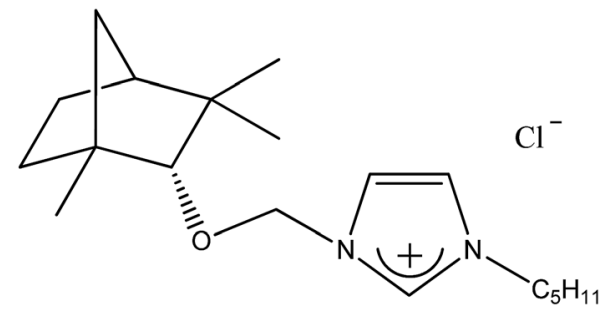

$\mathrm{C}_{5} \mathrm{H}_{11}$

1-[(1R)-endo-(+)-Fenchoxymethyl]-3-
pentylimidazolium chloride

$\left[\mathrm{C}_{5}-\mathrm{Im}-\mathrm{CH}_{2} \mathrm{O}-\mathrm{Fen}\right][\mathrm{Cl}]$

98.8

${ }^{a}$ Isolated yield after purification and drying. ${ }^{b}$ Accuracy $\pm 0.1 \%$.

chlorides were determined by a direct two-phase titration technique (EN ISO 2871-2: 2010 norm) and range from 99.1 to $99.7 \%$. The rest consists of water. All details are given in the Table 3 . The melting point, crystallization condition, and specific rotation of each imidazolium salt are also presented in Table 3.

All of the synthesized chlorides are solid. The melting point of chlorides with methyl substituent exceed $100{ }^{\circ} \mathrm{C}$, but it should be noted that the melting point of $\left[\mathrm{C}_{1}-\mathrm{Im}-\mathrm{CH}_{2} \mathrm{O}-\mathrm{Bor}\right][\mathrm{Cl}]$ is only slightly higher then $100{ }^{\circ} \mathrm{C}$ and is of: $103.7-104.5^{\circ} \mathrm{C}$. On the other hand the chlorides with pentyl substituent melt below $100{ }^{\circ} \mathrm{C}$ and these salts should be considered as ionic liquids, according to the definition. ${ }^{50}$ The general trend that can be observed for discussed CILs is that the chlorides with longer alkyl chain have lower melting temperatures than their analogs with a shorter alkyl chain.

The solubility test has been performed using popular polar and nonpolar solvents according to the method described by
Vogel et al. ${ }^{42}$ The results are presented in Table 4 . All of obtained chlorides are soluble in water, methanol, propanol, acetonitrile, chloroform, dimethylformamide and dimethyl sulfoxide at $20{ }^{\circ} \mathrm{C}$. The solubility of discussed salts in acetone, ethyl acetate, tetrahydrofuran and toluene at $20{ }^{\circ} \mathrm{C}$ is limited or completely not observed. The raising of the temperature of the test to $50^{\circ} \mathrm{C}$ and/or changing the substituent from methyl to pentyl of each salt significantly affect the increase of the solubility in conferred solvents. The synthesized salts are not soluble in diethyl ether and hexane even at elevated temperatures.

The structure and purity of all of the synthesized salts was confirmed by spectral analysis (for spectra see ESI $\dagger$ ). The purity was assessed by elemental analysis and HRMS analysis. All of the discussed quaternary chlorides were characterized by ${ }^{1} \mathrm{H}$ and ${ }^{13} \mathrm{C}$ NMR.

There are two characteristic doublets observed in ${ }^{1} \mathrm{H}$ NMR spectra of all of the discussed salts: one doublet around 5.60- 
Table 3 Properties of chiral ionic liquids (2-6)

\begin{tabular}{llllll}
\hline & Abbreviation & Melting & Crystallization & & Surfactant \\
CILs & {$\left[\mathrm{Cn}-\mathrm{Im}-\mathrm{CH}_{2} \mathrm{O}\right.$-Terpene $][\mathrm{Cl}]$} & $\operatorname{point}^{a}\left({ }^{\circ} \mathrm{C}\right)$ & solvents & Specific \\
rotation $^{c, d, e}[\alpha]_{\mathrm{D}}^{25}$
\end{tabular}

(1S)-endo-(-)-Borneol based chiral ionic liquids

3-Alkyl-1-[(1S)-endo-(-)-borneoxymethyl]imidazolium chlorides

$\begin{array}{lllllrr}\text { 1b } \quad\left[\mathrm{C}_{1}-\mathrm{Im}-\mathrm{CH}_{2} \mathrm{O}-\mathrm{Bor}\right][\mathrm{Cl}] & 103.7-104.5 & \text { Ethyl acetate/acetone } & \begin{array}{l}\text { Squared, regular, } \\ \text { plates }\end{array} & 99.7 & -47.72(c \text { 1.035) } \\ \text { 1c } & {\left[\mathrm{C}_{5}-\mathrm{Im}-\mathrm{CH}_{2} \mathrm{O}-\mathrm{Bor}\right][\mathrm{Cl}]} & 81.9-82.5 & \text { Ethyl acetate/acetone } & \begin{array}{l}\text { Long, regular } \\ \text { needles }\end{array} & 99.2 & -36.80(c 0.996)\end{array}$

(1R)-endo-(+)-Fenchol based chiral ionic liquids

3-Alkyl-1-[(1R)-endo-(+)-fenchoxymethyl $]$ imidazolium chlorides

$\begin{array}{lllllll}\text { 2b } & {\left[\mathrm{C}_{1}-\mathrm{Im}-\mathrm{CH}_{2} \mathrm{O}-\mathrm{Fen}\right][\mathrm{Cl}]} & 137.9-138.2 & \begin{array}{l}\text { Ethyl acetate/acetone/ } \\ \text { ethanol }\end{array} & \text { Regular needles } & 99.6 & +23.125(c 0.995) \\ \text { 2c } & {\left[\mathrm{C}_{5}-\mathrm{Im}-\mathrm{CH}_{2} \mathrm{O}-\mathrm{Fen}\right][\mathrm{Cl}]} & 60.7-61.4 & \text { Ethyl acetate/acetone } & \begin{array}{l}\text { Squared, regular, } \\ \text { plates }\end{array} & 99.1 & +26.51(c 1.007)\end{array}$

${ }^{a}$ Accuracy $\pm 0.1{ }^{\circ}$ C. ${ }^{b}$ Accuracy $\pm 0.1 \% .{ }^{c} c$ in methylene chloride. ${ }^{d}$ Standard uncertainty for specific rotation $u$ is $u(\alpha)= \pm 0.5^{\circ} .{ }^{e}$ Standard uncertainty for concentration $u$ is $u(c)= \pm 0.002 \mathrm{~g} / 100 \mathrm{~mL}$.

Table 4 Solubility of prepared CILs at $20^{\circ} \mathrm{C}$ and $50^{\circ} \mathrm{C}^{a}$

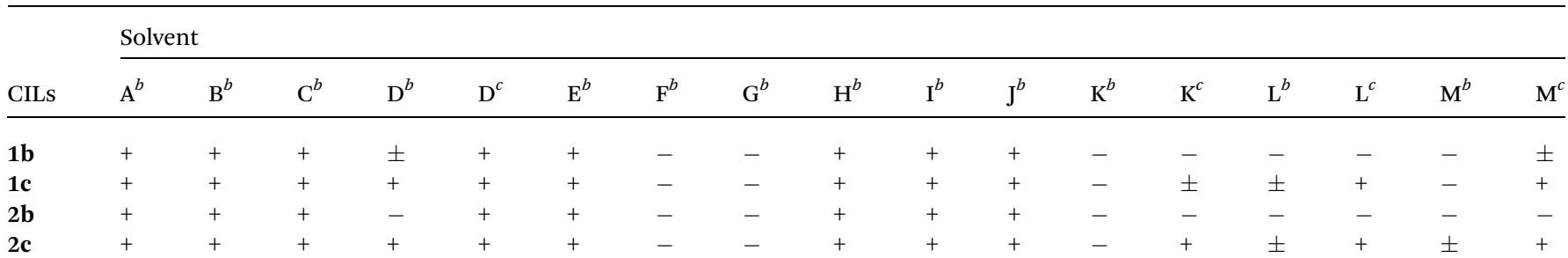

${ }^{a} \mathrm{~A}$ - water, B - methanol, C - propanol, D - acetone, E - acetonitrile, F - diethyl ether, G - hexane, H - chloroform, I - dimethylformamide (DMF), J dimethyl sulfoxide (DMSO), K - ethyl acetate, L - tetrahydrofuran (THF), M - toluene, '+' - complete soluble, ' \pm ' - limited solubility, '- ' - insoluble. ${ }^{b}$ At $20{ }^{\circ}$ C. ${ }^{c}$ At $50{ }^{\circ} \mathrm{C}$.

5.75 ppm and second doublet around 5.70-5.90 ppm, depending on considered chloride spectra. These signals described $\mathrm{CH}_{2}$ groups, which link the terpene moiety and imidazolium derivative, appear in the spectra in the form of two doublets as an $\mathrm{AB}$ spin system. This is a typical situation of the presence of diastereotopic protons, which are generally seen in the $\mathrm{CH}_{2}$ group of chiral molecules.

\section{Optimization of HPLC measurements}

Teicoplanin is widely used as the chiral stationary phase (CSP). Similarly to other macrocyclic glycopeptides, it can work either in normal phase (NP), reversed phase (RP) or polar ionic (PIM) modes. Depending on the mobile phase composition, different interactions such as hydrophobic interactions, electrostatic forces, steric hindrance or hydrogen bonding could be dominant in enantiorecognition. Studies performed by Thompson et $a l .{ }^{51}$ using a crown ether column, Flieger et $a .^{7}$ on a teicoplanin column and Sanganyado et $a l^{52}$ on a vancomycin based column showed that enantioresolution could be positively affected by addition of the liophilic ions to the mobile phase. As it was emphasized by the above researchers, the influence of ions on enantioselectivity followed the Hofmeister series.

In this experiment, the cooperative effect of liophilic ions, achiral ionic liquids (ACILs), four new (1S)-endo-(-)-borneol and $(1 R)$-endo-(+)-fenchol-type CILs with a teicoplanin based CSP was evaluated. Acidic enantiomers of mandelic acid, vanilmandelic acid, phenyllactic acid were chosen as model analytes. The role of the mobile phase additives was examined by altering their kind and concentration. Fig. 1 presents the effect of all the investigated mobile phase modifiers on the difference between the retention times of both enantiomers for each analyte. It can be observed that the influence of the modifiers on the $\Delta t_{\mathrm{r}}$ value varied according to their type.

The effect of chaotropic ionic additives in the mobile phase on the retention and enantioresolution on a teicoplanin column is known and has been described previously. ${ }^{7,51,52}$

A similar trend was previously described for achiral ionic liquid (ACILs) additives. ${ }^{53}$ Comparing the effects of ACILs, the less hydrophobic cations revealed a smaller influence on enantioresolution than more hydrophobic ones. It should be emphasized that the effect of ACILs was much stronger than one of chaotropic salts.

Comparison of data obtained for systems modified with new additives (Fig. 1) indicates that addition of the chiral ionic liquids (CILs) to the mobile phase is responsible for the highest improving of enantioselectivity. This phenomenon could be explained by the overall synergistic effect of both chiral components of the system with either teicoplanin or CIL. 


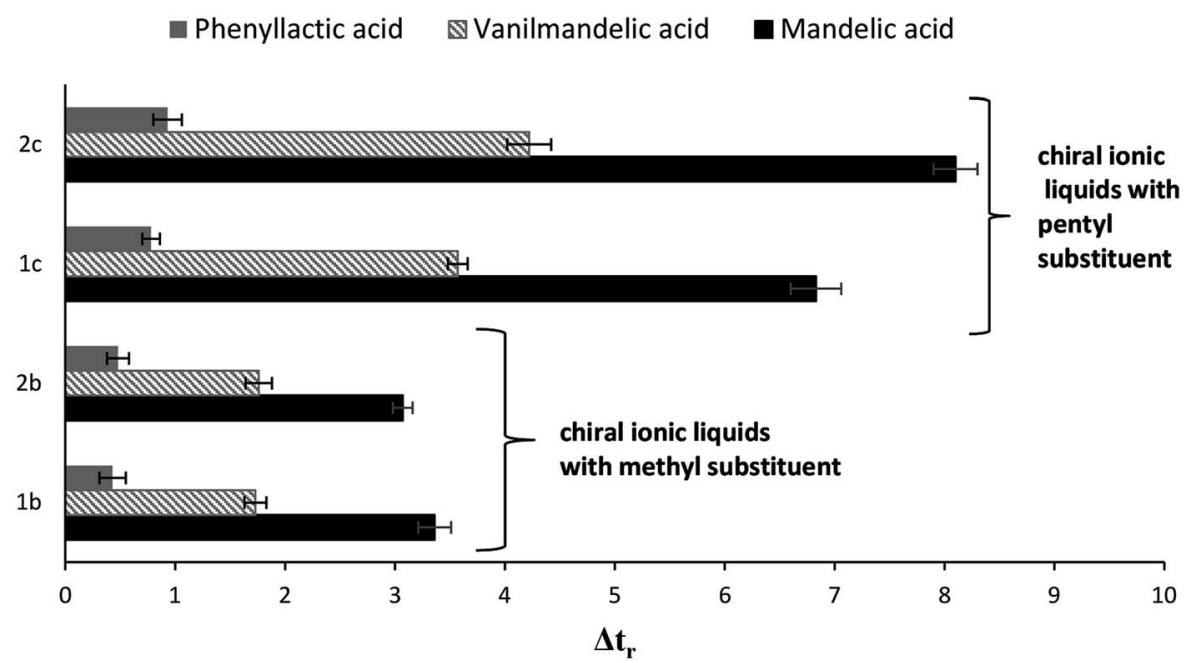

Fig. 1 Effect of type and amount of the mobile phase modifiers on retention time difference between enantiomers of investigated acids $\left(\Delta t_{\mathrm{r}}\right.$ ). Experimental conditions: the column: Astec Chirobiotic T, the mobile phase $10 \% \mathrm{MeOH} /$ water, detection wavelength: $220 \mathrm{~nm}$, flow rate: $1 \mathrm{~mL}$ $\min ^{-1}$, temperature $20^{\circ} \mathrm{C}$.

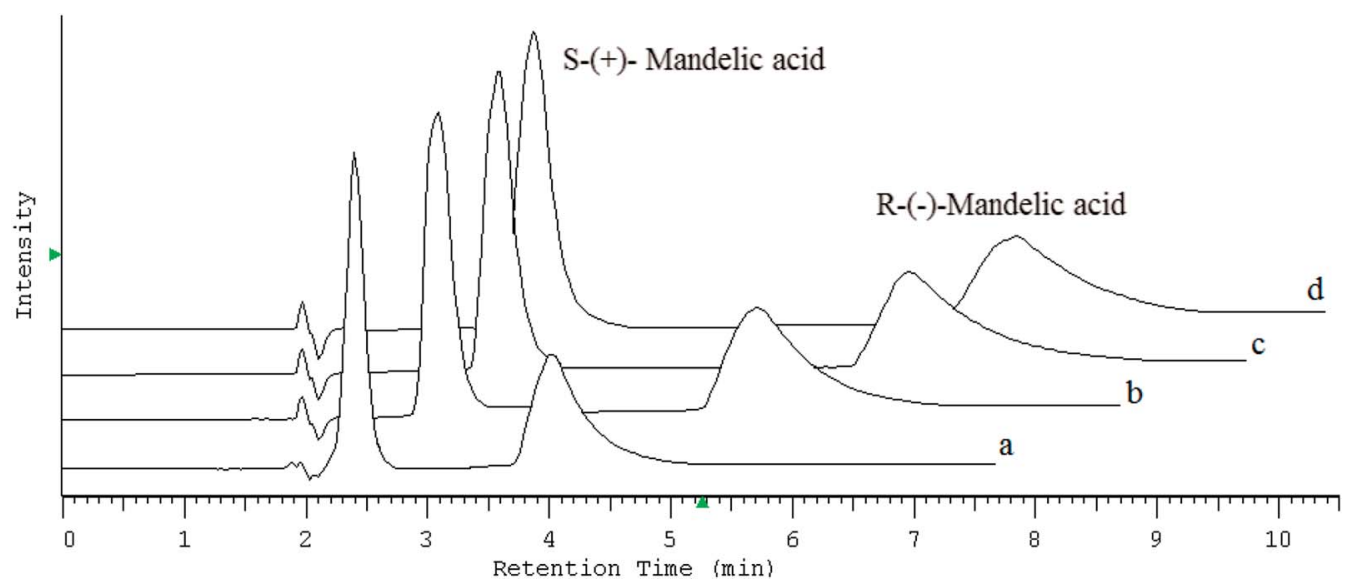

Fig. 2 Chromatogram of mandelic acid enantiomers resolution analyzing by the use of synergistic system containing teicoplanin and different concentration of $1 \mathrm{~b} \mathrm{CIL}$ (a) $5 \mathrm{mM}$ of $\mathrm{ClL}$ in $10 \% \mathrm{MeOH}$; (b) $10 \mathrm{mM}$ of $\mathrm{ClL}$ in $10 \% \mathrm{MeOH}$; (c) $15 \mathrm{mM}$ of $\mathrm{ClL}$ in $10 \% \mathrm{MeOH}$; (d) $20 \mathrm{mM}$ of CIL in $10 \%$ $\mathrm{MeOH}$.

Considering CILs, it should be stressed that the most important parameter influencing enantioseparation appears to be the length of the hydrocarbon chain at the N3 position of imidazolium ring. CILs possessing pentyl substituent at the N3 position exhibited a more beneficial effect on enantioselectivity than other derivatives with a methyl substituent, independently of the kind of terpene component. In other words, presence of $(1 S)$-endo-(-)-borneol, (1R)-endo-(+)-fenchol gives similar beneficial effects and without doubt, it contributes to the improvement of enantioseparation. However, the strategic importance is presented by the substituent at the N3 position.

Chromatogram shown in Fig. 2 that both the retention and separation of enantiomers increased with the increasing concentration of CILs in the mobile phase. Whereas, in order to obtain optimal enantioselectivity, $60 \mathrm{mM}$ of chaotropic salts should be added to the mobile phase, whereas in the case of CILs, a concentration of $20 \mathrm{mM}$ was sufficient.

\section{Thermodynamics}

The effect of temperature was evaluated over the range of 5$35{ }^{\circ} \mathrm{C}$. The enantioselectivity for investigated analytes using different CILs at the same concentration $20 \mathrm{mM}$ in the mobile phase increased when the temperature was decreased. In this study, we varied the mobile phase modifiers and measured the effect of temperature on the analytes' retention factor. Linear van't Hoff curves representing ln $k$ against $1 / T$ were obtained for the analytes. The determination coefficient $R^{2}$ values of linear plots ranged from 0.9672 to 0.9998 indicating uniform and constant retention mechanism of all analytes within the studied temperature range (Table 5). The thermodynamic functions were calculated for the binding interactions of enantiomers 
Table 5 Thermodynamic parameters obtained for acidic enantiomers by the use of synergistic system containing the teicoplanin chiral stationary phase and the elution system modified with tested CILS

\begin{tabular}{|c|c|c|c|c|c|c|c|c|c|}
\hline CILs & $\begin{array}{l}\text { Investigated } \\
\text { compounds }\end{array}$ & & $\Delta S^{0 *}\left(\mathrm{~kJ} \mathrm{~mol}^{-1} \mathrm{~K}^{-1}\right)$ & $\begin{array}{l}\Delta\left(\Delta S^{0}\right) \\
\left(\mathrm{kJ} \mathrm{mol}^{-1} \mathrm{~K}^{-1}\right)\end{array}$ & $\Delta H^{0}\left(\mathrm{~kJ} \mathrm{~mol}{ }^{-1}\right)$ & $\begin{array}{l}\Delta\left(\Delta H^{0}\right) \\
\left(\mathrm{kJ} \mathrm{mol}^{-1}\right)\end{array}$ & $\Delta G^{0}\left(\mathrm{~kJ} \mathrm{~mol}^{-1}\right)$ & $\begin{array}{l}\Delta\left(\Delta G^{0}\right) \\
\left(\mathrm{kJ} \mathrm{mol}^{-1}\right)\end{array}$ & $r^{2}$ \\
\hline \multirow[t]{4}{*}{$1 b$} & Mandelic acid & $S(+)$ & $-0.0282( \pm 0.0009)$ & 0.0164 & $-10.1639( \pm 0.5914)$ & 6.8939 & $-1.9023( \pm 0.0322)$ & 2.0924 & 0.9911 \\
\hline & \multirow[t]{2}{*}{ Vanilmandelic acid } & $S(+)$ & $-0.0456( \pm 0.0031)$ & \multirow[t]{2}{*}{0.0088} & $-15.8190( \pm 0.6552)$ & \multirow[t]{2}{*}{3.8677} & $-2.4622( \pm 0.0553)$ & \multirow[t]{2}{*}{1.2881} & 0.9981 \\
\hline & & $R(-)$ & $-0.0544( \pm 0.0053)$ & & $-19.6867( \pm 0.9991)$ & & $-3.7503( \pm 0.0608)$ & & 0.9988 \\
\hline & Phenyllactic acid & $S(+)$ & $-0.0296( \pm 0.0015)$ & 0.0038 & $-10.9903( \pm 0.4276)$ & 1.2812 & $-2.2973( \pm 0.0440)$ & 0.1750 & 0.9862 \\
\hline & Mandelic acid & $R(-)$ & $-0.0407( \pm 0.0011)$ & 0.0188 & $-17.4345( \pm 0.3792)$ & 7.9125 & $-5.4888( \pm 0.0728)$ & 2.3938 & 0.9965 \\
\hline & \multirow[t]{2}{*}{ Vanilmandelic acid } & $S(+)$ & $-0.0435( \pm 0.0061)$ & \multirow[t]{2}{*}{0.0077} & $-16.3728( \pm 0.7188)$ & \multirow[t]{2}{*}{3.6132} & $-3.6211( \pm 0.0773)$ & \multirow[t]{2}{*}{1.3573} & 0.9964 \\
\hline & & $R(-)$ & $-0.0512( \pm 0.0019)$ & & $-19.9860( \pm 0.5343)$ & & $-4.9784( \pm 0.0242)$ & & 0.9989 \\
\hline & \multirow{2}{*}{ Phenyllactic acid } & $S(+)$ & $-0.0251( \pm 0.0016)$ & \multirow[t]{2}{*}{0.0053} & $-10.8664( \pm 0.7112)$ & \multirow[t]{2}{*}{1.8050} & $-3.5027( \pm 0.0691)$ & \multirow[t]{2}{*}{0.2674} & 0.9845 \\
\hline & & $R(-)$ & $-0.0304( \pm 0.0020)$ & & $-12.6714( \pm 0.7386)$ & & $-3.7701( \pm 0.0526)$ & & 0.9851 \\
\hline \multirow[t]{2}{*}{$2 \mathbf{b}$} & Mandelic acid & $S(+)$ & $-0.0310( \pm 0.0018)$ & 0.0198 & $-10.6519( \pm 0.2946)$ & 8.0496 & $-1.5705( \pm 0.0307)$ & 2.2492 & 0.9972 \\
\hline & & $R(-)$ & $-0.0382( \pm 0.0022)$ & & $-13.5377( \pm 0.5913)$ & & $-2.3283( \pm 0.0490)$ & & 0.9936 \\
\hline $2 \mathrm{c}$ & Mandelic acid & $S(+)$ & $-0.0172( \pm 0.0009)$ & 0.0187 & $-8.0962( \pm 0.3026)$ & 7.8858 & $-3.0447( \pm 0.0611)$ & 2.4096 & 0.9672 \\
\hline & & $R(-)$ & $-0.0359( \pm 0.0016)$ & & $-15.9820( \pm 0.2989)$ & & $-5.4543( \pm 0.0630)$ & & 0.9983 \\
\hline & Vanilmandelic acid & $S(+)$ & $-0.0392( \pm 0.0029)$ & 0.0085 & $-15.1348( \pm 0.8004)$ & 3.8560 & $-3.6351( \pm 0.0801)$ & 1.3606 & 0.9943 \\
\hline & & $R(-)$ & $-0.0477( \pm 0.0033)$ & & $-18.9908( \pm 0.8591)$ & & $-4.9957( \pm 0.0785)$ & & 0.9981 \\
\hline & Phenyllactic acid & $S(+)$ & $-0.0200( \pm 0.0013)$ & 0.0037 & $-9.3915( \pm 0.4215)$ & 1.3735 & $-3.5326( \pm 0.0694)$ & 0.2923 & 0.9838 \\
\hline & & $R(-)$ & $-0.0237( \pm 0.0015)$ & & $-10.7650( \pm 0.5100)$ & & $-3.8249( \pm 0.0726)$ & & 0.9836 \\
\hline
\end{tabular}

transferring from the mobile phase to teicoplanin bonded stationary phase in the presence of CILs acting as additional chiral selectors.

The standard changes in enthalpy $\left(\Delta H^{0}\right)$, entropy $\left(\Delta S^{0 *}\right)$ and Gibbs free energy (at $\left.20{ }^{\circ} \mathrm{C}\right)\left(\Delta G^{0}\right)$ were calculated from the slopes and intercepts of the van't Hoff relationship.

The $\Delta H^{0}$ values calculated for all enantiomers were negative, indicating that the transfer of the enantiomers is enthalpically favored. The $\Delta H^{0}$ values were in the range from -10.16 to

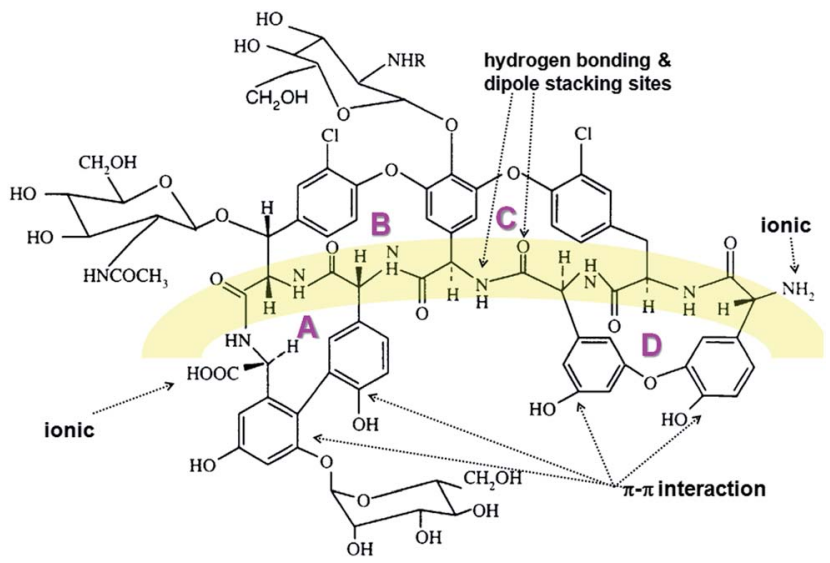

Fig. 3 The molecular structure of teicoplanin. The distinct four binding cavities are indicated (A, B, C and D). Additionally, the groups responsible for the most relevant interactions with $\mathrm{IL}$ are shown. $\mathrm{R}$ denotes $\mathrm{CH}_{3}$-decanoic acid.
$-21.26 \mathrm{~kJ} \mathrm{~mol}^{-1}$ for " $\mathrm{b}$ " series of CILs and from -8.10 to -19.99 $\mathrm{kJ} \mathrm{mol}{ }^{-1}$ for series "c".

Generally, the $\Delta H^{0}$ values, for the $R$ configuration were smaller than that for the $S$ enantiomers. This means that the interaction between the $R$ enantiomer was more favorable on the teicoplanin CSP in the presence of CILs. These results were reflected in the order of elution of the enantiomers, as the $S$ enantiomer was always eluted first. Similar trend was observed by other researchers applying glicopeptide CSPs with only one chiral selector. ${ }^{54}$ Regarding the $\Delta S^{0}$ values, negative values were also obtained. The $\Delta S^{0}$ values for the $S$ enantiomers were more positive than for the $R$ ones. Considering the presence of CIL as second chiral selector, the $\Delta S^{0}$ values were always more negative for the system containing series " $b$ " of CILs with a methyl functional group at the imidazolium ring regardless of the kind of terpene component in their structure. Change of CILs from the "c" in a series of "b" was associated with a decrease in entropy change. This change is related to the number of solvent molecules solvating the CSP, CIL and the analyte in the mobile phase and releasing during adsorption, or a reduced ability to move or rotate of the adsorbed analytes.

It should be emphasized that a change in the type of CILs in synergistic chromatographic system entailed a much larger difference in the value of $\Delta S^{0}$ than that observed for the $\Delta H^{0}$.

The total free energy change, $\Delta G^{0}$, was more negative for synergistic system containing CILs of a series "c". The smaller $\Delta G^{0}$ was visible in stronger retention of the analytes and better enantioresolution. 

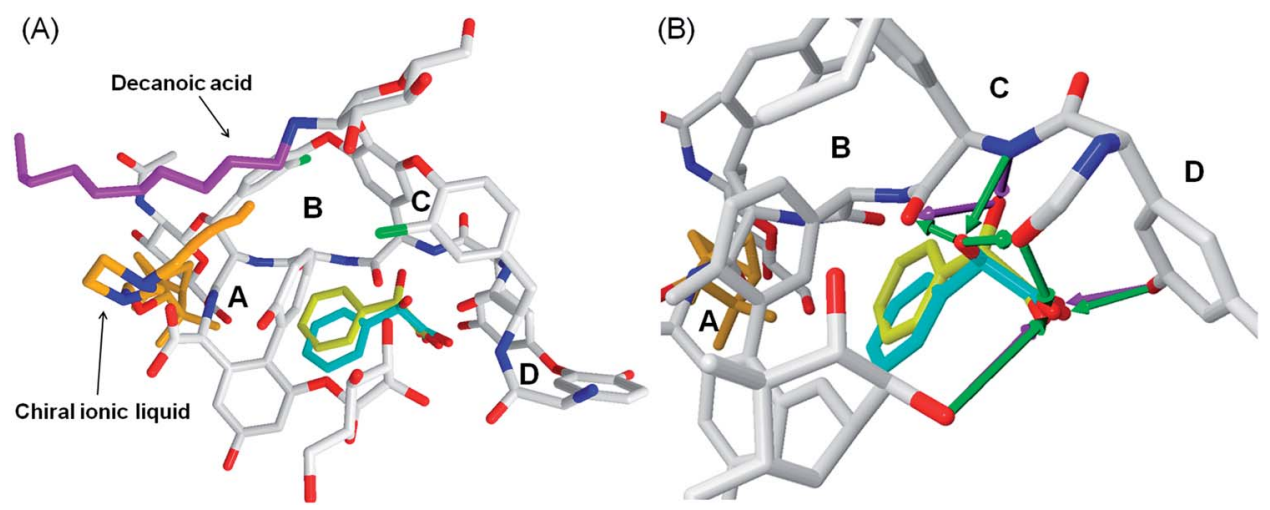

Fig. 4 The chiral ionic liquid $2 \mathrm{c}$-teicoplanin-R,S-mandelic acid complex. The $2 \mathrm{c}$ compound binds to cavities $\mathrm{B}, \mathrm{C}$ and $\mathrm{D}$. The hydrogen bonds were denoted as the green (teicoplanin- $R$-mandelic acid) and magenta (teicoplanin-S-mandelic acid) arrows. $R$-Mandelic acid is colored in blue, $S$-mandelic acid in yellow, teicoplanin in gray (except of most relevant oxygen and nitrogen atoms) and $2 c$ compound in orange. The decanoic acid chain is shown in purple.

The $\Delta\left(\Delta H^{0}\right), \Delta\left(\Delta S^{0}\right)$ values can be calculated as the following differences $\Delta H_{\mathrm{R}}^{0}-\Delta H_{\mathrm{S}}^{0}$ and $\Delta S_{\mathrm{R}}^{0}-\Delta S_{\mathrm{S}}^{0}$. The $\Delta\left(\Delta H^{0}\right)$ and $\Delta\left(\Delta S^{0}\right)$ values decreased with changing a series "b" into a series "c" of fenchol based CILs. Similar trend was observed for menthol based CILs. ${ }^{53}$ With the changing in $\Delta\left(\Delta H^{0}\right)$ and $\Delta\left(\Delta S^{0}\right)$, the difference in free energy, $\Delta\left(\Delta G^{0}\right)$, increased always with changing a series "b" into "c" of CILs regardless of the terpene component in their structure. Because the values $\left(\Delta \Delta G^{0}\right)$ contribute to enantioseparation in accordance with the following equation: $\Delta \Delta G^{0}=-R T \ln \alpha$, the best resolution of enantiomers for system containing a series "c" supports obtained results.

Furthermore, $\Delta \Delta G^{0}$ (at $20^{\circ} \mathrm{C}$ ) values derived from van't Hoff plots are in excellent agreement with the enantioselectivity factor $\alpha$ measured in chromatographic experiments:

$$
\begin{gathered}
\Delta \Delta G^{0}=1.4078( \pm 0.0874) \alpha-1.2444( \pm 0.1654), R^{2}=0.9629, s_{\mathrm{e}}= \\
0.31, F=259.62, n=10
\end{gathered}
$$

\section{The docking simulations}

Stereoselective binding of mandelic acid enantiomers into teicoplanin. The experimental data showed that the Chirobiotic $\mathrm{T}$ column was effective in separating acidic enantiomers. However, the addition of the chiral IL significantly improved the separation of the tested enantiomers. Based on the results of experimental measurements we expect that IL molecules may exhibit direct contact with teicoplanin and, by interactions of such type, facilitate separation of the stereoisomers considered. In order to explain the effect of (i) stereoconfiguration of the CIL molecule, and (ii) the length of its acyclic aliphatic chain on the separation of acidic enantiomers, the docking simulations were performed.

The teicoplanin molecule contains four binding cavities (AD), Fig. 3. All the ligands docked to teicoplanin in similar manner and they bind only to cavities B, C and D, Fig. 4 .

The positions of the $R$ - and $S$-mandelic acid molecules in the teicoplanin molecule are very similar to each other, however $R$ enantiomer can create more hydrogen bonds than the $S$ -
Table 6 The MolDock Score values obtained for teicoplanin complexes formed with $R$ - and $S$-mandelic acid vanilmandelic and phenyllactic acid either with presence or absence of CILs. The $\Delta$ parameter describes the differences between MolDock Score values

\begin{tabular}{|c|c|c|}
\hline Complex & $\begin{array}{l}\text { MolDock } \\
\text { Score } \\
\left(\mathrm{kJ} \mathrm{mol}^{-1}\right)\end{array}$ & $\begin{array}{l}\Delta=\text { complex } \\
\text { with } R \text {-enantiomer } \\
- \text { complex with } \\
S \text {-enantiomer } \\
\left(\mathrm{kJ} \mathrm{mol}^{-1}\right)\end{array}$ \\
\hline icoplanin- $R$-mandelic acid & -64.3 & -7.6 \\
\hline Teicoplanin- $S$-mandelic acid & -56.7 & \\
\hline Teicoplanin- $R$-vanilmandelic acid & -61.4 & -2.2 \\
\hline Teicoplanin-S-vanilmandelic acid & -59.2 & \\
\hline Teicoplanin- $R$-phenyllactic acid & -58.6 & -3.5 \\
\hline Teicoplanin-S-phenyllactic acid & -55.1 & \\
\hline 1b-teicoplanin- $R$-mandelic acid & -60.8 & -8.4 \\
\hline 1b-teicoplanin- $S$-mandelic acid & -52.4 & \\
\hline 1c-teicoplanin- $R$-mandelic acid & -63.1 & -10.2 \\
\hline 1c-teicoplanin- $S$-mandelic acid & -52.9 & \\
\hline 1b-teicoplanin- $R$-vanilmandelic acid & -59.5 & -3.9 \\
\hline 1b-teicoplanin- $S$-vanilmandelic acid & -55.6 & \\
\hline 1c-teicoplanin- $R$-vanilmandelic acid & -61.6 & -4.2 \\
\hline c-teicoplanin-S-vanilmandelic acid & -57.4 & \\
\hline b-teicoplanin- $R$-phenyllactic acid & -59.1 & -3.8 \\
\hline 1b-teicoplanin- $S$-phenyllactic acid & -55.3 & \\
\hline 1c-teicoplanin- $R$-phenyllactic acid & -63.1 & -4.1 \\
\hline 1c-teicoplanin-S-phenyllactic acid & -59.0 & \\
\hline 2b-teicoplanin- $R$-mandelic acid & -61.1 & -8.9 \\
\hline 2b-teicoplanin- $S$-mandelic acid & -52.2 & \\
\hline 2c-teicoplanin- $R$-mandelic acid & -64.2 & -11.9 \\
\hline 2c-teicoplanin- $S$-mandelic acid & -52.3 & \\
\hline 2b-teicoplanin- $R$-vanilmandelic acid & -63.4 & -4.6 \\
\hline 2b-teicoplanin- $S$-vanilmandelic acid & -58.8 & \\
\hline 2c-teicoplanin- $R$-vanilmandelic acid & -66.2 & -4.9 \\
\hline 2c-teicoplanin- $S$-vanilmandelic acid & -60.3 & \\
\hline 2b-teicoplanin- $R$-phenyllactic acid & -59.7 & -3.6 \\
\hline 2b-teicoplanin- $S$-phenyllactic acid & -56.1 & \\
\hline 2c-teicoplanin- $R$-phenyllactic acid & -60.2 & -3.8 \\
\hline 2c-teicoplanin-S-phenyllactic acid & 56.4 & \\
\hline
\end{tabular}
obtained for complexes with $R$ - and $S$-stereoisomers 
enantiomer. In the case of $R$-mandelic acid molecules the hydroxyl group, located at the asymmetric carbon atom, can create three hydrogen bonds (HBs): (i) one as an acceptor with the nitrogen of secondary amine; (ii) two HBs as a donor with oxygen of the diethyl ether moieties of teicoplanin, Fig. 4. Moreover, the stereoconfiguration of the molecule can determine the position of the carboxyl group of the given enantiomer and interactions created by this group with teicoplanin. The carboxyl oxygen atoms of $R$-mandelic acid can create three HBs (with hydroxyphenyl, 2-OH glucose moieties and oxygen of the diethyl ether moiety). In the case of $S$-mandelic acid, the carboxyl group is exploited as an two HBs acceptor, Fig. 4. The comparison of MolDock Score values characterizing the complexes including $R$ - and $S$-enantiomers suggests that the complexes formed with $R$-enantiomer are more stable; in each of the considered cases, the complexes including $R$-enantiomer exhibit the lower MolDock Score value in comparison to complexes with $S$-enantiomer, Table 6 . In the case of both $R$ and $S$-vanilmandelic acid, the addition of the hydroxyl and methoxyl moieties to the phenyl ring results in the creation of additional HBs with teicoplanin. These compounds can bind simultaneously to the A, B, C and D binding cavities (Fig. S1†). Moreover, for $R$ - and $S$-vanilmandelic acid, more favorable values of MolDock Score were observed in contrast to mandelic acid. The respective differences are close to $\sim 2 \mathrm{~kJ} \mathrm{~mol}^{-1}$, independently of the enantiomer.

The influence of the chiral IL on the stereoselective binding of the mandelic acid enantiomers to teicoplanin. Experimental data indicate that the addition the chiral ionic liquid to mobile phase improves the enantiomers separation. The addition of the chiral ionic liquid into mandelic acid-teicoplanin complex does not improve the MolDock values of $R$-mandelic acid-teicoplanin complex and even increases the MolDock value for $S$ mandelic acid interacting with teicoplanin. The difference between the MolDock Score values obtained for complexes formed by $R$ - and $S$-mandelic acid $(\Delta)$ and teicoplanin in the absence of IL equals to $-7.6 \mathrm{~kJ} \mathrm{~mol}^{-1}$. This parameter is larger (up to $-12 \mathrm{~kJ} \mathrm{~mol}^{-1}$ ) for complexes formed in the presence of chiral ionic liquids, Table 6 . This suggests the significant influence of the chiral ionic liquid component in the enantiomers separation and is consistent with the results found in experimental investigation. The above mentioned differences can be ascribed to the minor changes of the teicoplanin conformation that occur upon binding of the chiral IL molecule. Such differences can be observed especially in the area of the A binding cavity and involve mainly the spatial reorientation of the glucose moiety attached to the aromatic moiety.

Moreover, theoretical calculations showed that the separation-enhancement abilities of ILs can be significantly altered upon changing the length of the alkyl chains included in their molecular structure. The length of this chain affects differences between binding energies of $R$ - and $S$-mandelic acid to the chiral IL-teicoplanin complexes, expressed as MolDock Score values, Table 6 . Both the experimental and theoretical studies indicate that the alkyl chain length in the ionic liquid molecules is positively correlated with the stability of the mandelic acid-IL-teicoplanin complex, Table 6. Docking simulations revealed the molecular details of interactions between chiral IL and teicoplanin. The imidazole ring of chiral ILs creates the ionic bridge with the carboxyl moiety of teicoplanin, Fig. 5. Moreover, the alkyl group of the chiral IL can interact (hydrophobic interactions) with the decanoic aliphatic chain of teicoplanin. This interaction stabilizes the conformation of the teicoplanin decanoic chain and expose the binding cavities of teicoplanin to interaction with potential ligands. Moreover, we observed the steric adjustment between the IL terpene substituent and beta-D-glucosamine ring of teicoplanin (in 4C1 chair conformation), Fig. 5. The exocyclic moieties of both these rings exhibit the equatorial arrangement, which facilitates the contact between them. The change of the chiral IL stereoconfiguration is associated with the equatorial-axial inversion and will support the reorientation of IL molecule in

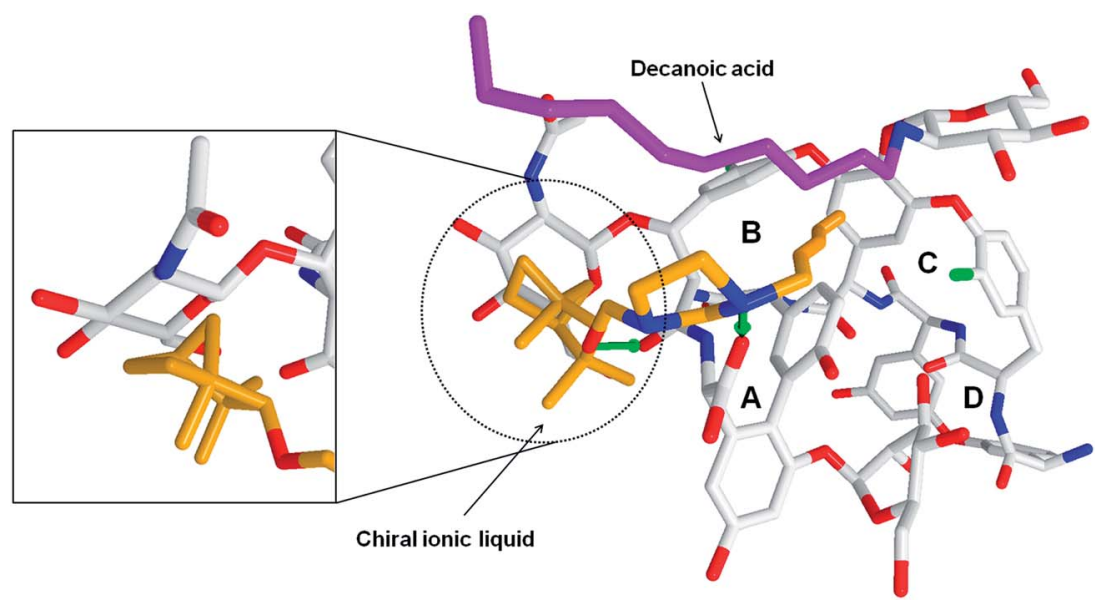

Fig. 5 The teicoplanin-2c complex. The imidazolum moiety of $2 c$ forms the ionic bridge with the carboxyl group of teicoplanin. Teicoplanin is presented in gray (except of most relevant oxygen and nitrogen atoms). The $2 c$ compound was colored in orange. The decanoic acid chain was given in purple. The left panel shows the steric adjustment between the terpene conformation of IL and beta-D-glucosamine moiety of teicoplanin. 
the vicinity of the ring, as well as loosing the favorable interactions with teicoplanin. The scheme of the molecular interactions within the mandelic acid-IL-teicoplanin complex is common for all studied chiral ILs, (Fig. S2†).

\section{Conclusion}

In summary, a novel group of terpene-based CILs derived from renewable sources from plants were prepared and characterized. As starting materials bicyclic terpene alcohols: $(1 S)$-endo$(-)$-borneol and $(1 R)$-endo-(+)-fenchol were selected. The quaternization (a specific type of Menschutkin reaction) does not required energy input. The physicochemical characteristics of obtained CILs, including spectral properties, melting point, type of the crystal shape, specific rotation and solubility in various solvents were comprehensively studied.

To our knowledge, this is the first study on the synergistic effect of chiral ionic liquid additives and a teicoplanin-based CSP in LC. The chiral recognition mechanism in such a synergistic system containing two chiral selectors has not been previously investigated.

We experimentally and theoretically proved that the addition of the chiral ionic liquids with a natural terpene substituent and elongation of the alkyl group of the chiral ILs affects the increasing differences in the binding energy of $R$-enantiomer in comparison to $S$-enantiomer binds to teicoplanin, thus determining better separations of the studied enantiomers.

The results of docking simulations clearly show the differences in the binding modes of acidic enantiomers interacting with teicoplanin. We indicated that: (i) both of the mandelic acid enantiomers bind into the $\mathrm{C}$ and $\mathrm{D}$ binding cavities of teicoplanin; (ii) $R$-mandelic acid exhibits more favorable interactions with teicoplanin in comparison to $S$-mandelic acid which is correlated with the number of intermolecular hydrogen bonds. We revealed that the presence of chiral ionic liquid affects the mandelic acid enantiomers binding into teicoplanin. Namely, it increases the stability of the teicoplaninmandelic acid complex which is due to the greater amount of hydrogen bonding that appears in such complex. Secondly, the difference between stabilities of the complexes including $R$ - and $S$-enantiomers of mandelic acid is enhanced in the presence of CIL. Finally, the elongation of the alkyl chain present in the IL molecules additionally promotes both the binding strength and the enantiospecific effects that occur in mandelic acid binding to teicoplanin. We also observed that the stereoconfiguration of IL may influence its interaction with teicoplanin.

\section{Acknowledgements}

This research was financed by the National Science Centre (Poland) grant no. 2013/09/D/ST5/03904.

\section{References}

1 Q. Q. Baltazar, S. K. Leininger and J. L. Anderson, J. Chromatogr. A, 2008, 1182, 119-127.
2 J. L. Anderson and D. W. Armstrong, Anal. Chem., 2003, 75, 4851-4858.

3 W. Qin, H. Wei and S. F. Y. Li, J. Chromatogr. A, 2003, 985, 447-454.

4 X. Xiao, L. Zhao, X. Liu and S. Jiang, Anal. Chim. Acta, 2004, 519, 207-211.

5 J. Flieger and A. Czajkowska-Żelazko, J. Sep. Sci., 2011, 34, 733-739.

6 Y. Wang, M. Tian, W. Bi and K. H. Row, Int. J. Mol. Sci., 2009, 10, 2591-2610.

7 J. Flieger, Anal. Lett., 2009, 42, 1632-1649.

8 V. Maier, J. Horáková, J. Petr, D. Drahoňovský and J. Ševcík, J. Chromatogr. A, 2006, 1103, 337-343.

9 P. Laamanen, S. Busi, M. Lahtinen and R. Matilainen, J. Chromatogr. A, 2005, 1095, 164-171.

10 J. G. Huddleston, H. D. Willauer, R. P. Swatloski, A. E. Visser and R. D. Rogers, Chem. Commun., 1998, 1765-1766.

11 J. F. Liu, G. B. Jiang, Y. G. Chi, Y. Q. Cai, Q. X. Zhou and J. T. Hu, Anal. Chem., 2003, 75, 5870-5876.

12 N. Fontanals, F. Borrull and R. M. Marce, TrAC, Trends Anal. Chem., 2012, 41, 15-26.

13 J. Flieger, M. Tatarczak-Michalewska, A. Groszek and El. Blicharska, Anal. Lett., 2016, 49, 1997-2005.

14 J. Flieger and A. Czajkowska-Żelazko, Food Chem., 2015, 166, 150-157.

15 K. E. Gutowski, G. A. Broker, H. D. Willauer, J. G. Huddleston, R. P. Swatloski, J. D. Holbrey and R. D. Rogers, J. Am. Chem. Soc., 2003, 125, 6632-6633.

16 D. Han and K. H. Row, Molecules, 2010, 15, 2405-2426.

17 J. Flieger, El. B. Grushka and A. Czajkowska-Zelazko, Austin J. Anal. Pharm. Chem., 2014, 1, 1009.

18 A. Berthod, M. J. Ruiz-Ángel and S. Carda-Broch, J. Chromatogr. A, 2008, 1184, 6-18.

19 C. D. Tran and I. Mejac, J. Chromatogr. A, 2008, 1204, 204209.

20 S. Rizvi and S. A. Shamsi, Anal. Chem., 2006, 78, 7061-7069.

21 Y. Francois, A. Varenne, E. Juillerat, D. Villemin and P. Gareil, J. Chromatogr. A, 2007, 1155, 134-141.

22 B. Wang, J. He, V. Bianchi and S. A. Shamsi, Electrophoresis, 2009, 30, 2812-2819.

23 J. Zhang, Y. Du, Q. Zhang and Y. Lei, Talanta, 2014, 119, 193201.

24 Y. Francois, A. Varenne, E. Juillerat, D. Villemin and P. Gareil, J. Chromatogr. A, 2007, 1155, 134-141.

25 Y. Zhang, S. Du, Z. Feng, Y. Du and Z. Yan, Anal. Bioanal. Chem., 2016, 408, 2543-2555.

26 L. M. Yuan, Y. Han, Y. Zhou, X. Meng, Z. Li, M. Zi and Y. Chang, Anal. Lett., 2006, 39, 1439-1449.

27 P. Kodali and A. M. Stalcup, J. Liq. Chromatogr. Relat. Technol., 2014, 37, 893-906.

28 Q. Liu, K. Wu, F. Tang, L. Yao, F. Yang, Z. Nie and S. Yao, Chem.-Eur. J., 2009, 15, 9889-9896.

29 Y. X. Yang, J. Li and X. Y. Jiang, J. Cent. South Univ., 2013, 20, 1173-1177.

30 H. Qing, X. Jiang and J. Yu, Chirality, 2014, 26, 160-165.

31 Z. Zhou, X. Li, X. Chen and X. Hao, Anal. Chim. Acta, 2010, 678, 208-214. 
32 G. Qian, H. Song and S. Yao, J. Chromatogr. A, 2016, 1429, 127-133.

33 J. Pernak, M. Niemczak, Ł. Chrzanowski, Ł. Ławniczak, P. Fochtman, K. Marcinkowska and T. Praczyk, Chem.-Eur. J., 2016, 22, 12012-12021.

34 J. Neumann, S. Steudte, C.-W. Cho, J. Tröming and S. Stolte, Green Chem., 2014, 16, 2174-2184.

35 J. Feder-Kubis, B. Szefczyk and M. Kubicki, J. Org. Chem., 2015, 80, 237-246.

36 K. Erfurt, I. Wandzik, K. Walczak, K. Matuszek and A. Chrobok, Green Chem., 2014, 16, 3508-3514.

37 J. M. M. Araújo, C. Florindo, A. B. Pereiro, N. S. M. Vieira, A. A. Matias, C. M. M. Duarte, L. P. N. Rebelo and I. M. Marrucho, RSC Adv., 2014, 4, 28126-28132.

38 Z. Wang, Q. Wang, Y. Zhang and W. Bao, Tetrahedron Lett., 2005, 46, 4657-4660.

39 J. C. Plaquevent, J. Levillain, F. Guillen, C. Malhiac and A. C. Gaumont, Chem. Rev., 2008, 108, 5035-5060.

40 J. Pernak, J. Feder-Kubis, A. Cieniecka-Rosłonkiewicz, C. Fischmeister, S. Griffin and R. D. Rogers, New J. Chem., 2007, 31, 879-892.

41 J. Pernak and J. Feder-Kubis, Chem.-Eur. J., 2005, 11, 44414449.

42 A. I. Vogel, A. R. Tatchell, B. S. Furnis, A. J. Hannaford and P. W. G. Smith, Vogel's Textbook of Practical Organic Chemistry, Longman, 5th edn, 1989.

43 Y. C. Liu, Y. S. Li, S. Y Lyu, L. J. Hsu, Y. H. Chen, Y. T. Huang, H. C. Chan, C. J. Huang, G. H. Chen, C. C. Chou, M. D. Tsai and T. L. Li, Nat. Chem. Biol., 2011, 7, 304-309.

44 M. D. Hanwell, D. E. Curtis, D. C. Lonie, T. Vandermeersch, E. Zurek and G. R. Hutchison, J. Cheminf., 2012, 4, 17-33.

45 A. K. Rappe, C. J. Casewit, K. S. Colwell, W. A. Goddard III and W. M. Skiff, J. Am. Chem. Soc., 1992, 114, 10024-10035. 46 J. J. P. Stewart, J. Mol. Model., 2007, 13, 1173-1213.
47 M. J. Frisch, G. W. Trucks, H. B. Schlegel, G. E. Scuseria, M. A. Robb, J. R. Cheeseman, G. Scalmani, V. Barone, B. Mennucci, G. A. Petersson, H. Nakatsuji, M. Caricato, X. Li, H. P. Hratchian, A. F. Izmaylov, J. Bloino, G. Zheng, J. L. Sonnenberg, M. Hada, M. Ehara, K. Toyota, R. Fukuda, J. Hasegawa, M. Ishida, T. Nakajima, Y. Honda, O. Kitao, H. Nakai, T. Vreven, J. A. Montgomery Jr, J. E. Peralta, F. Ogliaro, M. Bearpark, J. J. Heyd, E. Brothers, K. N. Kudin, V. N. Staroverov, R. Kobayashi, J. Normand, K. Raghavachari, A. Rendell, J. C. Burant, S. S. Iyengar, J. Tomasi, M. Cossi, N. Rega, J. M. Millam, M. Klene, J. E. Knox, J. B. Cross, V. Bakken, C. Adamo, J. Jaramillo, R. Gomperts, R. E. Stratmann, O. Yazyev, A. J. Austin, R. Cammi, C. Pomelli, J. W. Ochterski, R. L. Martin, K. Morokuma, V. G. Zakrzewski, G. A. Voth, P. Salvador, J. J. Dannenberg, S. Dapprich, A. D. Daniels, Ö. Farkas, J. B. Foresman, J. V. Ortiz, J. Cioslowski and D. J. Fox, Gaussian 09, Revision E.01, Gaussian, Inc., Wallingford CT, 2009.

48 A. Plazinska, M. Kolinski, I. W. Wainer and K. Jozwiak, J. Mol. Model., 2013, 19, 4919-4930.

49 A. Roy, A. Kucukural and Y. Zhang, Nat. Protoc., 2011, 5, 725738.

50 P. Wasserscheid and W. Keim, Angew. Chem., Int. Ed., 2000, 39, 3772-3789.

51 R. A. Thompson, Z. Ge, N. Grinberg, D. Ellison and P. Tway, Anal. Chem., 1995, 67, 1580-1587.

52 E. Sanganyado, Z. Lu and J. Gan, J. Chromatogr. A, 2014, 1368, 82-88.

53 J. Flieger, J. Feder-Kubis, M. Tatarczak-Michalewska, A. Płazińska, A. Madejska and M. Swatko-Ossor, J. Sep. Sci., DOI: $10.1002 /$ jssc.201700197, in press.

54 A. Péter, G. Török, D. W. Armstrong, G. Toth and D. Tourwe, J. Chromatogr. A, 1998, 828, 177-190. 